\title{
Effects of Anethole in Nociception Experimental Models
}

\author{
Alessandra Mileni Versuti Ritter, ${ }^{1}$ Franciele Queiroz Ames, ${ }^{1}$ \\ Fernando Otani, ${ }^{1}$ Rubia Maria Weffort de Oliveira, ${ }^{2}$ \\ Roberto Kenji Nakamura Cuman, ${ }^{1}$ and Ciomar Aparecida Bersani-Amado ${ }^{1}$ \\ ${ }^{1}$ Department of Pharmacology and Therapeutics, Laboratory of Inflammation, State University of Maringá, \\ Avenida Colombo 5790, 87020-900 Maringá, PR, Brazil \\ ${ }^{2}$ Department of Pharmacology and Therapeutics, Laboratory of Brain Ischemia and Neuroprotection, \\ State University of Maringá, Maringá, PR, Brazil
}

Correspondence should be addressed to Ciomar Aparecida Bersani-Amado; cabamado@uem.br

Received 26 June 2014; Revised 30 August 2014; Accepted 1 September 2014; Published 25 November 2014

Academic Editor: Jen-Kun Cheng

Copyright (C) 2014 Alessandra Mileni Versuti Ritter et al. This is an open access article distributed under the Creative Commons Attribution License, which permits unrestricted use, distribution, and reproduction in any medium, provided the original work is properly cited.

\begin{abstract}
This study investigated the antinociceptive activity of anethole (anethole 1-methoxy-4-benzene (1-propenyl)), major compound of the essential oil of star anise (Illicium verum), in different experimental models of nociception. The animals were pretreated with anethole $(62.5,125,250$, and $500 \mathrm{mg} / \mathrm{kg})$ one hour before the experiments. To eliminate a possible sedative effect of anethole, the open field test was conducted. Anethole $(62.5,125,250$, and $500 \mathrm{mg} / \mathrm{kg})$ showed an antinociceptive effect in the writhing model induced by acetic acid, in the second phase of the formalin test $(125$ and $250 \mathrm{mg} / \mathrm{kg})$ in the test of glutamate $(62.5,125$, and $250 \mathrm{mg} / \mathrm{kg})$, and expresses pain induced by ACF $(250 \mathrm{mg} / \mathrm{kg})$. In contrast, anethole was not able to increase the latency time on the hot plate and decrease the number of flinches during the initial phase of the formalin test in any of the doses tested. It was also demonstrated that anethole has no association with sedative effects. Therefore, these data showed that anethole, at all used doses, has no sedative effect and has an antinociceptive effect. This effect may be due to a decrease in the production/release of inflammatory mediators.
\end{abstract}

\section{Introduction}

Anethole (1-methoxy-4-benzene-[1-propenyl]) is a phenylpropanoid that is principally obtained from the essential oi of star anise (Illicium verum), anise (Pimpinella anisum), and sweet anise (Foeniculum vulgare) and comprises more than $90 \%$ of the essential oil of these plants [1,2]. Anethole is found in lower concentrations in the essential oils of lemon balm (6.1\%), cilantro (0.5\%), and basil (0.08\%) [3].

Anethole appears to be responsible for most of the properties attributed to the essential oil of star anise, with antioxidant [4], anticarcinogenic [5, 6], anti-inflammatory $[3,7]$, and antihypernociceptive [8] actions, among others. Some studies have demonstrated that the antioxidant effect of anethole is attributable to its ability to sequester free radicals, thus increasing the intracellular levels of glutathione and glutathione-S-transferase and inhibiting lipid peroxidation [3]. The ability to suppress the incidence and development of carcinomas is not yet well understood $[3,9]$. Choo et al. [6] recently demonstrated that its anticarcinogenic activity is related to inhibitory effects on cellular adhesion and tumor invasion and the suppression of proteolytic enzymes through the nuclear factor $\kappa \mathrm{B}$ (NF- $\kappa \mathrm{B})$ signaling pathway.

Recently we showed that oral anethole administration in experimental animals inhibited the formation of inflammatory exudate and migration of leukocytes in models of pleurisy induced by carrageenan and ear edema induced by croton oil, antihypernociceptive activity in models of acute and persistent inflammatory pain induced by carrageenan and complete Freund adjuvant (CFA), respectively. We also demonstrated that anethole reduces the recruitment of neutrophils in experimental models of in vitro chemotaxis and in situ microcirculation [10], in addition to immunomodulatory activity through a reduction of the migration of lymphocytes 
and macrophages induced by sheep erythrocytes antigens (unpublished date).

Some of these effects have been related to the inhibitory effect of anethole on the production or release of inflammatory mediators, such as prostaglandins, nitric oxide [7], interleukin-1 (IL-1), tumor necrosis factor (TNF), and IL-17 [8]. Additionally, we demonstrated that anethole did not alter the plasma levels of transaminases (aspartate transaminase and alanine transaminase, i.e., markers of hepatic lesions) or morphological and histological profiles of hepatic tissue when administered for 7 days [8].

Despite these findings, there was a need to continue the studies on the antinociceptive activity of anethole. Therefore, our aims in this study were to investigate the role of anethole in various experimental models of nociception. The mechanisms involved in this activity have been discussed.

\section{Materials and Methods}

2.1. Animals. The experiments were performed in male Swiss mice, weighing 20-30 g. They were obtained from the breeding stock of the Laboratory of Inflammation, University of Maringá, PR, Brazil. The mice were housed in a temperaturecontrolled room on a $12 \mathrm{~h} / 12 \mathrm{~h}$ light/dark cycle with ad libitum access to standard rat chow and water. The experimental protocols were approved by the Committee for Animal Studies of the State University of Maringá (125/2010, CEEA).

2.2. Protocol of Treatment. The animals were treated orally with anethole $(62.5,125,250$, and $500 \mathrm{mg} / \mathrm{kg})$, the reference antiinflammatory drug indomethacin $(10 \mathrm{mg} / \mathrm{kg})$, or saline $(10 \mathrm{~mL} / \mathrm{kg})$ as a negative control. The schedules of treatment were determined on the basis of previous literature $[7,8]$. The drugs were prepared immediately prior to use.

2.3. Acetic Acid-Induced Writhing. The mice were treated with anethole $(62.5,125,250$, and $500 \mathrm{mg} / \mathrm{kg}$, p.o.), indomethacin (10 mg/kg, p.o.), or saline (10 mL/kg, p.o.). One hour after treatment, acetic acid solution ( $0.6 \%)$ was injected into the peritoneal cavity. The mice were then placed in a larger glass cylinder, and the intensity of nociceptive behavior was quantified by counting the total number of writhes that occurred 0-20 min after the injection.

2.4. Formalin Test. The formalin-induced paw kicking test was performed as described by Hunskaar and Hole [11], with some modifications. The mice were pretreated with different doses of anethole $(62.5,125,250$, and $500 \mathrm{mg} / \mathrm{kg}$, p.o.), indomethacin (10 mg/kg, p.o.), or saline $(10 \mathrm{~mL} / \mathrm{kg}$, p.o.). One hour after treatment, $20 \mu \mathrm{L}$ of a $2.0 \%$ formalin solution was injected into the plantar surface of the hind paw. The animals were then individually placed in glass cylinders. Nociceptive behavior was determined by the number of flinches induced by formalin. Kicking of the injected paw was counted from 0 to $5 \mathrm{~min}$ (first phase) and from 15 to $40 \mathrm{~min}$ (second phase) after the formalin injection. These phases correspond to neurogenic and inflammatory pain responses, respectively.

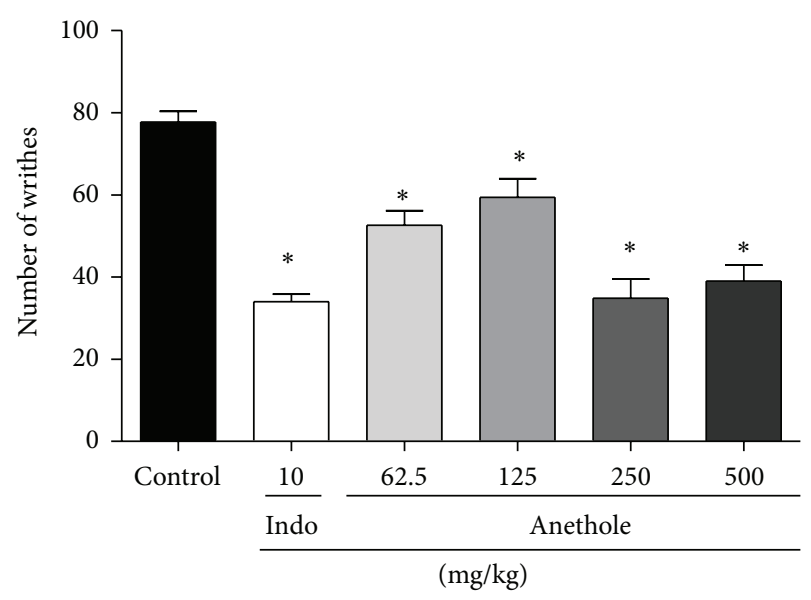

FIGURE 1: Effect of oral administration of anethole on acetic acidinduced writhing in mice. $0.6 \%$ acetic acid was intraperitoneally injected to mice $60 \mathrm{~min}$ after administration of the anethole (62.5, 125,250 , and $500 \mathrm{mg} / \mathrm{kg}$, p.o.) and indomethacin (10 mg/kg, p.o.). Data are represented as mean \pm S.E.M. ${ }^{*} P<0.05$, compared with the control group (one-way ANOVA followed by Tukey test).

2.5. Complete Freund Adjuvant-Induced Pain. The animals were pretreated with anethole $(250 \mathrm{mg} / \mathrm{kg}$, p.o.) or saline (10 mL/kg, p.o.). One hour later, $20 \mu \mathrm{L}$ of complete Freund adjuvant (CFA) was injected into the plantar surface of the hind paw. The animals were observed from 0 to $20 \mathrm{~min}$, and the time they spent licking the injected paw was recorded and considered indicative of nociception.

2.6. Hot-Plate Test. The animals were placed on a $55.0 \pm$ $0.5^{\circ} \mathrm{C}$ hot plate (Ugo Basile Varese, Italy). Reaction times were recorded when the animals licked or kicked the hind paw or jumped $15,30,60$, and 90 min after administration of anethole $(125,250$, and $500 \mathrm{mg} / \mathrm{kg}$, p.o. $)$, saline $(10 \mathrm{~mL} / \mathrm{kg}$, p.o.), or the reference drug meperidine $(50 \mathrm{mg} / \mathrm{kg}$, i.p.). The baseline was the mean reaction time of each animal, and a cutoff of $30 \mathrm{~s}$ was used to avoid tissue damage.

2.7. Glutamate Test. The glutamate test was performed according to Beirith et al. 2002 [12], with some modifications. The animals were pretreated with anethole $(62.5,125$, and $250 \mathrm{mg} / \mathrm{kg}$, p.o.). One hour later, $20 \mu \mathrm{L}$ of a glutamate solution $(10 \mu \mathrm{mol} / \mathrm{paw})$ was injected under the ventral surface of the left hind paw. After the intraplantar injection of glutamate, the animals were individually placed into glass cylinders (20 $\mathrm{cm}$ diameter), and the time spent licking and biting the injected paw was recorded with a chronometer. This time was considered indicative of pain. The mice were observed for $15 \mathrm{~min}$. Paw edema was measured $15 \mathrm{~min}$ after glutamate injection using plethysmometry.

2.8. Open-Field Test. Locomotor activity was quantified for $5 \mathrm{~min}$ in an open field that consisted of a white Plexiglas box $(45 \times 45 \mathrm{~cm})$ without physical barriers. One hour after anethole treatment $(62.5,125,250$, and $500 \mathrm{mg} / \mathrm{kg}$, p.o. $)$ and 7 days after anethole treatment $(250 \mathrm{mg} / \mathrm{kg})$, each mouse was 
TABLE 1: Reaction time of animals in hot plate test: $0,15,30,60$, and $90 \mathrm{~min}$ after treatment of anethole $(62.5,125,250$, and 500 mg/kg, p.o.) and meperidine $(50 \mathrm{mg} / \mathrm{kg}$, i.p.).

\begin{tabular}{|c|c|c|c|c|c|}
\hline \multirow{2}{*}{ Treatment $(\mathrm{mg} / \mathrm{kg})$} & \multicolumn{5}{|c|}{ Reaction time (s) } \\
\hline & $0 \mathrm{~min}$ & $15 \mathrm{~min}$ & $30 \mathrm{~min}$ & $60 \mathrm{~min}$ & $90 \mathrm{~min}$ \\
\hline Control & $8.9 \pm 0.5$ & $8.4 \pm 0.6$ & $8.6 \pm 0.5$ & $7.9 \pm 0.4$ & $7.7 \pm 0.9$ \\
\hline Anethole 62.5 & $6.8 \pm 0.5$ & $6.8 \pm 0.6$ & $7.2 \pm 1.1$ & $10.7 \pm 1.4$ & $8.4 \pm 0.6$ \\
\hline Anethole 125 & $8.2 \pm 0.4$ & $8.5 \pm 0.9$ & $11.3 \pm 1.1$ & $9.1 \pm 0.5$ & $10.8 \pm 1.0$ \\
\hline Anethole 250 & $7.6 \pm 0.7$ & $11.9 \pm 0.6$ & $12.3 \pm 0.8$ & $11.1 \pm 1.2$ & $8.7 \pm 0.5$ \\
\hline Anethole 500 & $7.3 \pm 0.4$ & $10.9 \pm 0.8$ & $10.9 \pm 1.2$ & $10.5 \pm 0.6$ & $9.8 \pm 0.7$ \\
\hline Meperidine & $7.6 \pm 0.5$ & $25.4 \pm 1.7^{*}$ & $14.0 \pm 1.3^{*}$ & $14.2 \pm 1.2^{*}$ & $12.4 \pm 0.7$ \\
\hline
\end{tabular}

Control: animals that received oral treatment of saline $(10 \mathrm{mg} / \mathrm{kg})$ : Anethole $62.5,125,250$, and 500: animals that received oral treatment of anethole in doses of $62.5,125,250$, and $500 \mathrm{mg} / \mathrm{kg}$, respectively; meperidine: animals that received intraperitoneal injection of meperidine in doses of $50 \mathrm{mg} / \mathrm{kg}$. Data are represented as mean \pm S.E.M. ${ }^{*} P<0.05$, compared with the control group (one-way ANOVA followed by Tukey test).

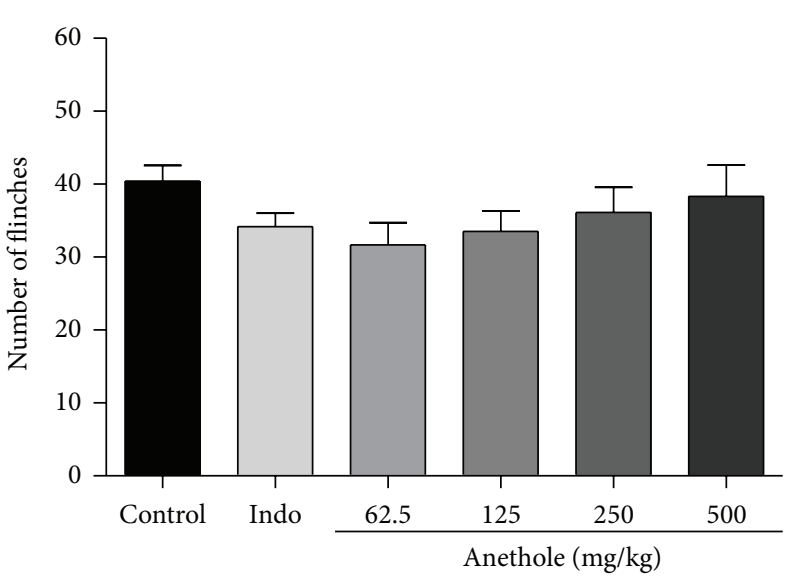

(a)

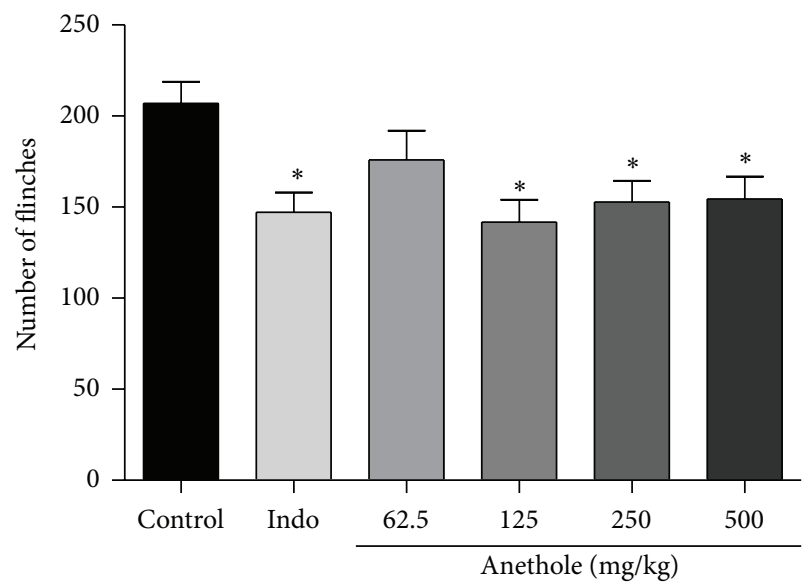

(b)

FIGURE 2: The effects of anethole on the early phase (a) (0-5 min) and late phase (b) (15-40 min) on $2 \%$ formalin-induced inflammation in mice. $20 \mu \mathrm{L}$ of $2 \%$ formalin solution was injected into the dorsal surface of the hind paw of mice 60 min after administration of the anethole $(62.5,125,250$, and $500 \mathrm{mg} / \mathrm{kg}$, p.o. $)$ and indomethacin $\left(10 \mathrm{mg} / \mathrm{kg}\right.$, p.o.). Data are represented as mean \pm S.E.M. ${ }^{*} P<0.05$, compared with the control group (one-way ANOVA followed by Tukey test).

gently placed in the center of the box, and locomotor activity was scored. Behavior was continuously recorded by a video camera that was placed over the apparatus and encoded using ANY-maze software.

2.9. Statistical Analysis. The statistical analysis was performed using Prism software (GraphPad, San Diego, CA, USA) and analysis of variance (ANOVA). Values of $P<0.05$ were considered statistically significant.

\section{Results}

3.1. Acetic Acid-Induced Writhing. After the acetic acid solution injection, the mice exhibited $7.7 \pm 2.6$ abdominal constriction in the control group. Treatment with different doses of anethole or indomethacin significantly suppressed abdominal constrictions compared with controls. The inhibition percentages were $56 \%$ for indomethacin and $32 \%, 24 \%$, $55 \%$, and $50 \%$ for anethole at doses of $62.5,125,250$, and $500 \mathrm{mg} / \mathrm{kg}$, respectively (Figure 1).
3.2. Formalin Test. Treatment with indomethacin and the different doses of anethole did not reduce the number of kicks (flinches) compared with the control group in the first phase of the formalin test (Figure 2(a)), which assesses neuropathic pain. However, indomethacin and anethole at doses of 125 and $250 \mathrm{mg} / \mathrm{kg}$ significantly reduced the number of kicks (flinches) induced by formalin compared with control group in the second phase of the test, which assesses inflammatory pain. The inhibition percentages were $29 \%$ for indomethacin and $31 \%, 26 \%$, and $25 \%$ for anethole at doses of 125,250 , and $500 \mathrm{mg} / \mathrm{kg}$, respectively (Figure 2(b)).

3.3. Hot-Plate Test. The animals in the control group remained on the hot plate for an average of $8.4 \pm 0.5$ seconds. Meperidine $(50 \mathrm{mg} / \mathrm{kg})$ significantly increased the response latency compared with the control group (25.4 $\pm 1.7,14.0 \pm$ $1.3,14.2 \pm 1.2$ seconds) 15,30 , and $60 \mathrm{~min}$ after treatment, respectively. However, anethole at different doses did not significantly increase the response latency on the hot plate at any of the periods analyzed (Table 1). 


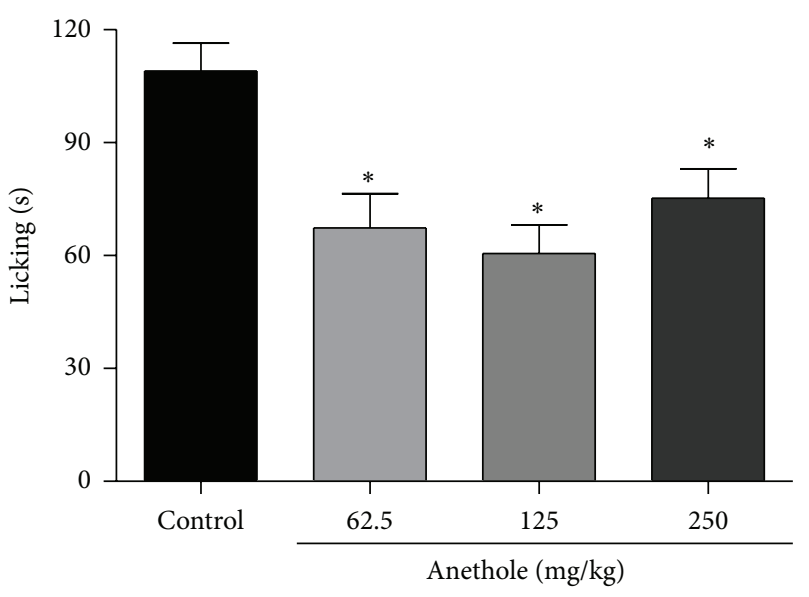

(a)

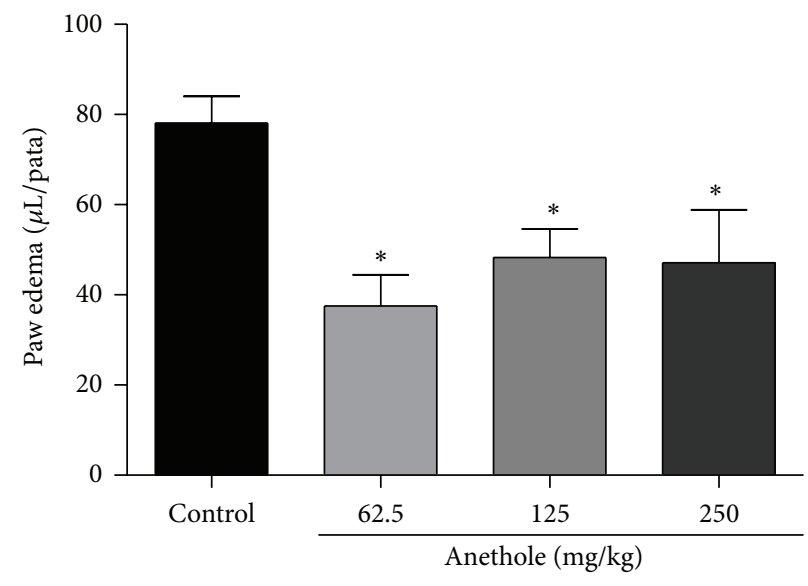

(b)

FIGURE 3: Effect of oral treatment of anethole $(62.5,125$, and $250 \mathrm{mg} / \mathrm{kg})$ on time spent licking (a) and paw edema (b) after intraplantar injection of glutamate $(10 \mu \mathrm{mol} / \mathrm{paw})$ in mice. Data are represented as mean \pm S.E.M. ${ }^{*} P<0.05$, compared with the control group (one-way ANOVA followed by Tukey test).

3.4. Glutamate Test. The glutamate injection induced a nociceptive response, reflected by the time the animals spent licking the paw and paw edema formation. Anethole at doses of $62.5,125$, and $250 \mathrm{mg} / \mathrm{kg}$ exerted significant antinociceptive activity compared with the control group. The inhibition percentages were $38 \%, 44 \%$, and $31 \%$ for the $62.5,125$, and $250 \mathrm{mg} / \mathrm{kg}$ doses, respectively (Figure 3(a)). Treatment with anethole significant reduced paw edema compared with the control group, with inhibition percentages of $52 \%, 38 \%$, and $40 \%$ for the doses of $62.5,125$, and $250 \mathrm{mg} / \mathrm{kg}$, respectively (Figure 3(b)).

3.5. Complete Freund Adjuvant-Induced Pain. Complete Freund adjuvant induced an average of $88 \pm 4.7$ flinches in the control group $20 \mathrm{~min}$ after CFA injection. Anethole at a dose of $250 \mathrm{mg} / \mathrm{kg}$ reduced $39 \%$ the number of flinches induced by CFA (Figure 4).

3.6. Open-Field Test. A major concern in experiments that evaluate the analgesic action of novel agents is whether pharmacological treatment causes other behavioral alterations, such as alterations in motor coordination or sedation that can be misinterpreted as analgesia. Treatment with different doses of anethole did not reduce duration locomotion in the openfield test compared with the control group (Figure 5(a)). After 7 days of daily treatment with anethole $(250 \mathrm{mg} / \mathrm{kg})$, the animals did not exhibit locomotor changes in the open-field test (Figure 5(b)).

\section{Discussion}

In this study, we demonstrated the antinociceptive effect of anethole in various experimental models of pain. Anethole significantly reduced peripheral nociception (i) in the abdominal constriction model, (ii) in the second phase of the formalin test, (iii) induced pain by CFA, and (iv) by

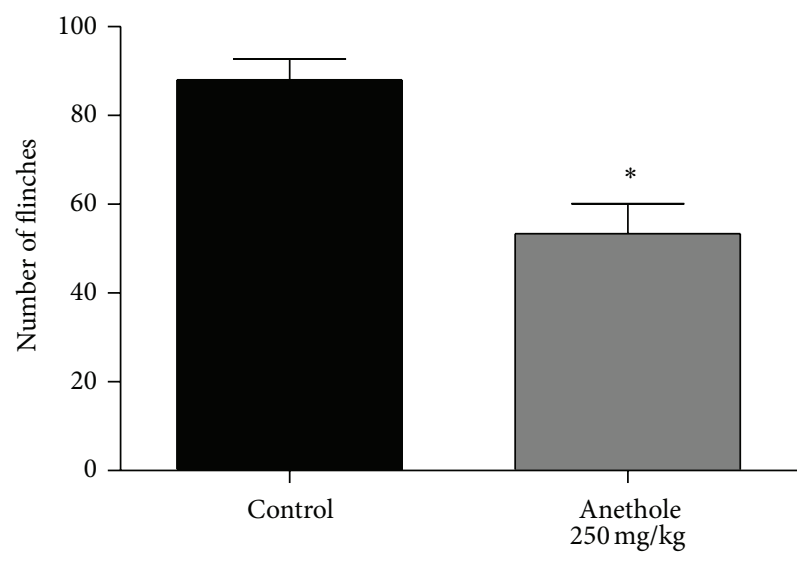

Figure 4: Effect of oral treatment of anethole $(250 \mathrm{mg} / \mathrm{kg})$ on number of flinches induced by $20 \mu \mathrm{L}$ of complete Freund adjuvant (CFA). Data are represented as mean \pm S.E.M. ${ }^{*} P<0.05$, compared with the control group (one-way ANOVA followed by Tukey test).

glutamate. However, it had no central antinociceptive effect, with no effects in the hot-plate test or first phase of the formalin test.

The test of abdominal constriction induced by acetic acid has been used as a screening tool for the evaluation of anti-inflammatory and analgesic agents that act at the peripheral level. Acetic acid indirectly acts on the release of endogenous substances, such as glutamate, bradykinin, serotonin, histamine, and sympathomimetic amines, culminating in nociceptor activation. It also increases the release of prostaglandins that are responsible for nociceptor sensitization $[13,14]$. Nociceptors that respond to acetic acid depend on the release of some cytokines, such as TNF, IL-1, and IL-8, from macrophages and mastocytes in the peritoneal cavity [15-17]. We verified that anethole reduced acetic acidinduced abdominal constrictions similar to indomethacin at 


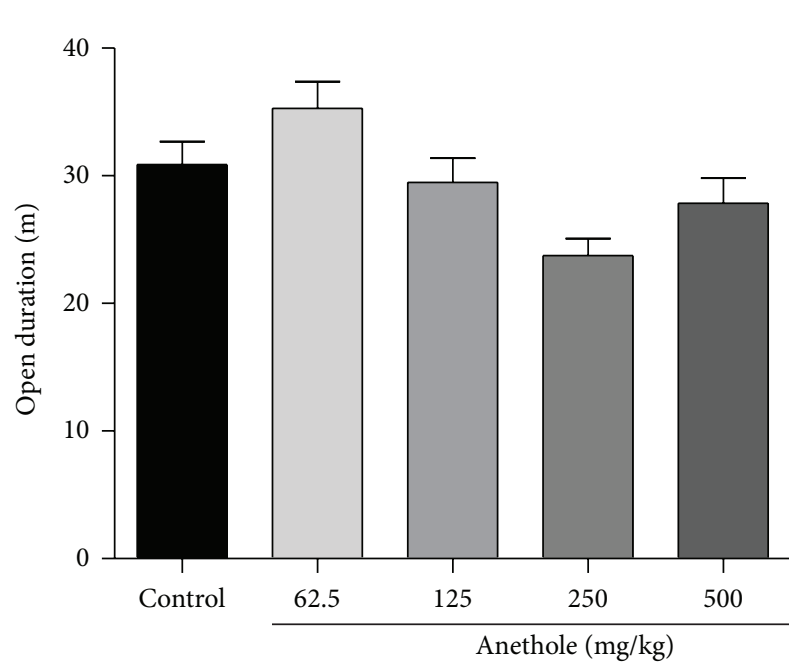

(a)

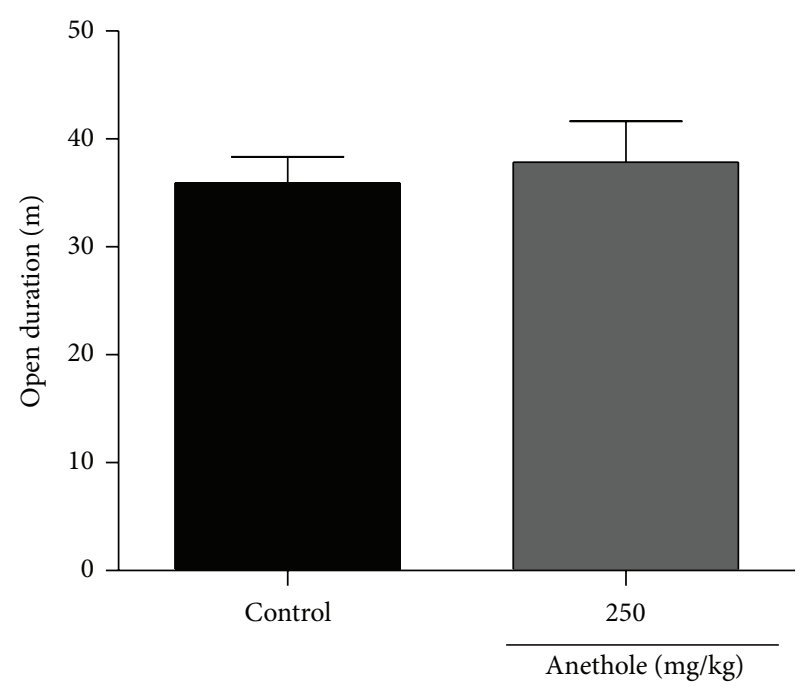

(b)

Figure 5: Effect of oral treatment of anethole on open-field test. The animals were treated with a single dose $(62.5,125,250$, and 500 mg/kg) and for 7 days $\left(250 \mathrm{mg} / \mathrm{kg}\right.$ ) of anethole. Data are represented as mean \pm S.E.M. ${ }^{*} P<0.05$, compared with the control group (one-way ANOVA followed by Tukey test).

doses of 250 and $500 \mathrm{mg} / \mathrm{kg}$, indicating that the antinociceptive activity reached the maximum effect in these doses. This action may be attributable to the inhibition of one or more inflammatory mediators that are involved in this activity.

Given that the formalin test presents distinct phases, it is considered a useful tool for elucidating the mechanism of action of compounds because it allows differentiation between neurogenic/central pain (first phase) and inflammatory/peripheral pain (second phase). The first phase occurs immediately after an intraplantar injection of formalin and is characterized by intense neurogenic pain that is generated by the direct activation of nociceptors through C-fiber stimulation. The second and longer phase appears to be caused by the release of nociceptive mediators, such as histamine, serotonin, prostaglandin, and bradykinin $[16,18]$. Analgesic drugs, such as narcotics, act via different mechanisms mainly at the central level in the initial and late phases of the test, inhibiting both phases equally. Drugs with peripheral action, such as dexamethasone and nonsteroidal antiinflammatory drugs, only inhibit the second phase of formalin-induced nociception $[19,20]$. Pretreatment with anethole at different doses did not affect the nociceptive response in the initial phase (neurogenic pain) showing that it has no central effect; however, it significantly inhibited the number of flinches in the second phase of the test, indicating that the compound diminished peripheral pain.

To confirm this observation, we used the hot-plate test because it measures supraspinal (central) analgesia produced by drugs. Anti-inflammatory drugs with a peripheral mechanism of action have no effect on thermal nociception [21, 22]. Pretreatment with anethole at different doses did not increase the time spent on the hot-plate, indicating that it has no central antinociceptive action as also observed by formalininduced nociception test.
Glutamate is the principal excitatory neurotransmitter in the central nervous system. Recently, the presence of glutamate receptors (GluRs) in peripheral sensorial terminal areas has also been reported, demonstrating its role in peripheral nociceptive transduction. Carlton [23] reported that an intraplantar injection of glutamate triggered painrelated behavior, suggesting that manipulation of peripheral glutamatergic systems can provide a new approach for the treatment of pain of peripheral origin. If so, then this may meet currently unmet clinical needs.

Experimentally, glutamate injection in the animals paws results in an intense, short-duration nociceptive response associated with the formation of paw edema. One of the mediators that are responsible for these events is nitric oxide. The release of nitric oxide increases the synthesis or release of other inflammatory mediators, such as cytokines and prostanoids, resulting in an increase in inflammatory and nociceptive responses [24]. Beirith et al. [12] demonstrated that nitric oxide inhibition reduces nociception and paw edema. Anethole may be a potential alternative therapeutic for the control of peripheral pain, given that it reduced nociception in several experimental models, including a test with glutamate. In the present study, we found that anethole treatment reduced both inflammatory and nociceptive responses. Thus, anethole may influence the synthesis or release of nitric oxide. This hypothesis is supported by the results of Domiciano et al. [7] that reported a reduction of nitric oxide levels in pleural exudate of animals treated with anethole.

The pain induced by CFA causes the activation or release of various endogenous inflammatory mediators, such as histamine, serotonin, and kinins, through the degranulation of resident mastocytes, in addition to an increase in prostaglandins caused by the activation of cyclooxygenases 
and cytokines, such as IL- $1 \beta$ and TNF, that stimulate nociceptors $[16,18,24-26]$. Anethole has been recently shown to reduce the synthesis or release of cytokines (IL-1 $\beta$ and TNF) and prostaglandin $\mathrm{E}_{2}$ in models of inflammation induced by CFA and carrageenan [7, 8]. Indeed, Ponte et al. [27] reported that anethole reduced paw edema produced by histamine, bradykinin, and serotonin, demonstrating the influence of anethole on these inflammatory mediators release. Our data showed that anethole treatment $(250 \mathrm{mg} / \mathrm{kg})$ in a single dose reduced the number of flinches induced by CFA demonstrating its antinociceptive activity probably by acting in mechanisms of different inflammatory mediators released during inflammatory process.

In this study, we also found that treatment with anethole in a single dose or daily administrated for 7 days did not alter motor activity in the open field test. Thus, our data indicates that anethole had no sedative effects at the doses tested. Importantly, when a compound has a sedative effect, this can interfere with the results in tests of nociception $[28,29]$.

Taken together, the data show that although the anethole has an important antinociceptive effect, the effective dose and the intensity of the effect are variable, according to the experimental model used, which may be dependent on the type and concentration of the mediators produced or released in the response.

\section{Conclusions}

The present work provides evidence that anethole exerts a peripheral antinociceptive effect without causing sedation. This antinociceptive action may be the result of a reduction of the production or release of inflammatory mediators. For all this we propose that the anethole might represent an interesting therapeutic alternative in inflammatory and painful diseases.

\section{Conflict of Interests}

All authors declare that there is no conflict of interests.

\section{Acknowledgments}

The authors thank Jailson Araujo Dantas and Celia Regina Miranda for technical assistance. This study was supported by grants from the Coordenadoria de Aperfeiçoamento de Pessoal de Nível Superior (CAPES), Fundação Araucária, and Conselho Nacional de Desenvolvimento Científico e Tecnológico (CNPq), Brazil.

\section{References}

[1] J.-F. Yang, C.-H. Yang, H.-W. Chang et al., "Chemical composition and antibacterial activities of Illicium verum against antibiotic-resistant pathogens," Journal of Medicinal Food, vol. 13, no. 5, pp. 1254-1262, 2010.

[2] P. M. G. Soares, R. F. Lima, A. F. Pires, E. P. Souza, M. S. Assreuy, and D. N. Criddle, "Effects of anethole and structural analogues on the contractility of rat isolated aorta: involvement of voltagedependent $\mathrm{Ca}^{2+}$-channels," Life Sciences, vol. 81, no. 13, pp. 10851093, 2007.

[3] G. B. N. Chainy, S. K. Manna, M. M. Chaturvedi, and B. B. Aggarwal, "Anethole blocks both early and late cellular responses transduced by tumor necrosis factor: effect on NF$\kappa \mathrm{B}, \mathrm{AP}-1, \mathrm{JNK}, \mathrm{MAPKK}$ and apoptosis," Oncogene, vol. 19, no. 25, pp. 2943-2950, 2000.

[4] R. S. Freire, S. M. Morais, F. E. A. Catunda Jr., and D. C. S. N. Pinheiro, "Synthesis and antioxidant, anti-inflammatory and gastroprotector activities of anethole and related compounds," Bioorganic and Medicinal Chemistry, vol. 13, no. 13, pp. 43534358, 2005.

[5] M. M. Al-Harbi, S. Qureshi, M. Raza, M. M. Ahmed, A. B. Giangreco, and A. H. Shah, "Influence of anethole treatment on the tumour induced by Ehrlich ascites carcinoma cells in paw of Swiss albino mice," European Journal of Cancer Prevention, vol. 4, no. 4, pp. 307-318, 1995.

[6] E. J. Choo, Y.-H. Rhee, S.-J. Jeong et al., "Anethole exerts antimetatstaic activity via inhibition of matrix metalloproteinase 2/9 and AKT/mitogen-activated kinase/nuclear factor kappa B signaling pathways," Biological and Pharmaceutical Bulletin, vol. 34, no. 1, pp. 41-46, 2011.

[7] T. P. Domiciano, M. M. D. O. Dalalio, E. L. Silva et al., "Inhibitory effect of anethole in nonimmune acute inflammation," Naunyn-Schmiedeberg's Archives of Pharmacology, vol. 386, no. 4, pp. 331-338, 2013.

[8] A. M. V. Ritter, T. P. Domiciano, W. A. Verri Jr. et al., "Antihypernociceptive activity of anethole in experimental inflammatory pain," Inflammopharmacology, vol. 21, no. 2, pp. 187-197, 2013.

[9] R. A. Lubet, V. E. Steele, I. Eto, M. M. Juliana, G. F. Kelloff, and C. J. Grubbs, "Chemopreventive efficacy of anethole trithione, Nacetyl-L-cysteine, miconazole and phenethylisothiocyanate in the DMBA-induced rat mammary cancer model," International Journal of Cancer, vol. 72, no. 1, pp. 95-101, 1997.

[10] C. F. Estevão-Silva, R. Kummer, F. C. Fachini-Queiroz et al., "Anethole and eugenol reduce in vitro and in vivo leukocyte migration induced by fMLP, LTB4, and carrageenan," Journal of Natural Medicines, vol. 68, no. 3, pp. 567-575, 2014.

[11] S. Hunskaar and K. Hole, "The formalin test in mice: dissociation between inflammatory and non-inflammatory pain," Pain, vol. 30, no. 1, pp. 103-114, 1987.

[12] A. Beirith, A. R. S. Santos, and J. B. Calixto, "Mechanisms underlying the nociception and paw oedema caused by injection of glutamate into the mouse paw," Brain Research, vol. 924, no. 2, pp. 219-228, 2002.

[13] S. S. Mendes, R. R. Bomfim, H. C. R. Jesus et al., "Evaluation of the analgesic and anti-inflammatory effects of the essential oil of Lippia gracilis leaves," Journal of Ethnopharmacology, vol. 129, no. 3, pp. 391-397, 2010.

[14] Z.-R. Lai, W.-H. Peng, Y.-L. Ho et al., "Analgesic and antiinflammatory activities of the methanol extract of kalanchoe gracilis (L.) DC stem in mice," The American Journal of Chinese Medicine, vol. 38, no. 3, pp. 529-546, 2010.

[15] Z. Zhang and L. Shi, "Anti-inflammatory and analgesic properties of cis-mulberroside A from Ramulus mori," Fitoterapia, vol. 81, no. 3, pp. 214-218, 2010.

[16] A. C. de Queiroz, D. P. de Lira, T. D. L. M. F. Dias et al., “The antinociceptive and anti-inflammatory activities of Piptadenia stipulacea Benth. (Fabaceae)," Journal of Ethnopharmacology, vol. 128, no. 2, pp. 377-383, 2010. 
[17] L. Ming-Tatt, S. I. Khalivulla, M. N. Akhtar et al., "Antinociceptive activity of a synthetic curcuminoid analogue, 2,6-bis(4-hydroxy-3-methoxybenzylidene)cyclohexanone, on nociception-induced models in mice," Basic \& Clinical Pharmacology \& Toxicology, vol. 110, no. 3, pp. 275-282, 2012.

[18] A. Tjolsen, O.-G. Berge, S. Hunskaar, J. H. Rosland, and K. Hole, "The formalin test: an evaluation of the method," Pain, vol. 51, no. 1, pp. 5-17, 1992.

[19] S. Hunskaar, O. B. Fasmer, and K. Hole, "Formalin test in mice, a useful technique for evaluating mild analgesics," Journal of Neuroscience Methods, vol. 14, no. 1, pp. 69-76, 1985.

[20] M. Shibata, T. Ohkubo, H. Takahashi, and R. Inoki, "Modified formalin test: characteristic biphasic pain response," Pain, vol. 38, no. 3, pp. 347-352, 1989.

[21] V. M. Couto, F. C. Vilela, D. F. Dias et al., "Antinociceptive effect of extract of Emilia sonchifolia in mice," Journal of Ethnopharmacology, vol. 134, no. 2, pp. 348-353, 2011.

[22] N. B. Eddy and D. Leimback, "Synthetic analgesics: II. Dithienylbutenyl-and dithienylbutylamines," Journal of Pharmacology and Experimental Therapeutics, vol. 107, pp. 385-393, 1953.

[23] S. M. Carlton, "Peripheral excitatory amino acids," Current Opinion in Pharmacology, vol. 1, no. 1, pp. 52-56, 2001.

[24] H. M. Onga, A. S. Mohamada, N. A. Makhtara et al., "Antinociceptive activity of methanolic extract of Acmella uliginosa (Sw.) Cass," Journal of Ethnopharmacology, vol. 133, no. 1, pp. 227-233, 2011.

[25] J. Zaringhalam, A. Akbari, E. Tekieh, H. Manaheji, and S. Rezazadeh, "Achillea santolina reduces serum interlukin-6 level and hyperalgesia during complete Freund's adjuvant-induced inflammation in male Wistar rats," Chinese Journal of Integrative Medicine, vol. 8, no. 12, pp. 1180-1189, 2010.

[26] T. B. Nguelefack, R. C. Dutra, A. F. Paszcuk, E. L. Andrade, L. A. Tapondjou, and J. B. Calixto, "Antinociceptive activities of the methanol extract of the bulbs of Dioscorea bulbifera L. var sativa in mice is dependent of NO-cGMP-ATP-sensitive-K+ channel activation," Journal of Ethnopharmacology, vol. 128, no. 3, pp. 567-574, 2010.

[27] E. L. Ponte, P. L. Sousa, M. V. A. P. Rocha et al., "Comparative study of the anti-edematogenic effects of anethole and estragole," Pharmacological Reports, vol. 64, no. 4, pp. 984-990, 2012.

[28] L. V. Panlilio, M. Solinas, S. A. Matthews, and S. R. Goldberg, "Previous exposure to THC alters the reinforcing efficacy and anxiety-related effects of cocaine in rats," Neuropsychopharmacology, vol. 32, no. 3, pp. 646-657, 2007.

[29] A. H. Swiergiel and A. J. Dunn, "Effects of interleukin-1 $\beta$ and lipopolysaccharide on behavior of mice in the elevated plusmaze and open field tests," Pharmacology Biochemistry and Behavior, vol. 86, no. 4, pp. 651-659, 2007. 


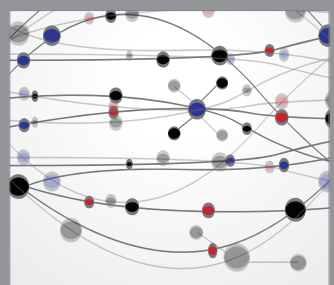

The Scientific World Journal
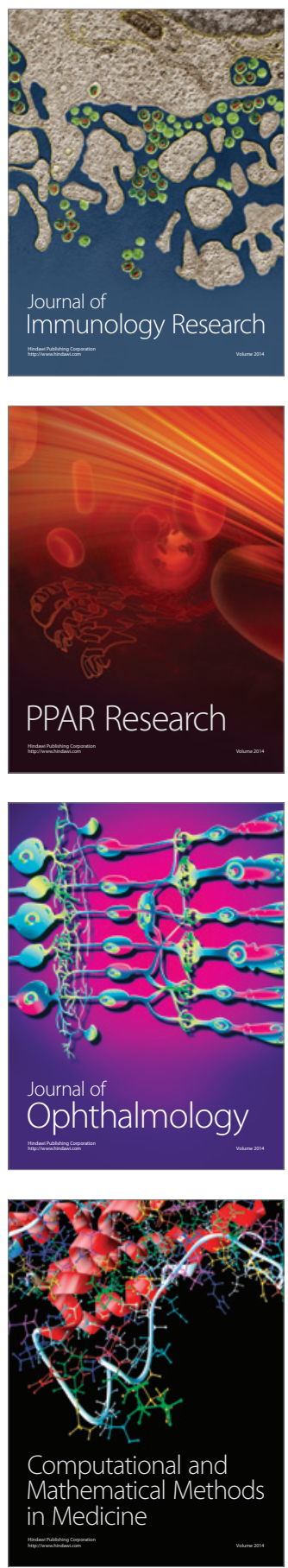

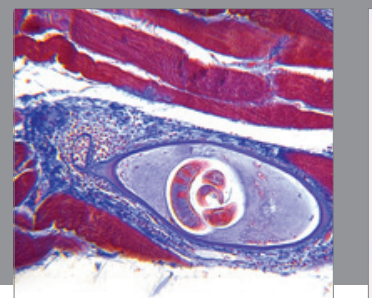

Gastroenterology

Research and Practice
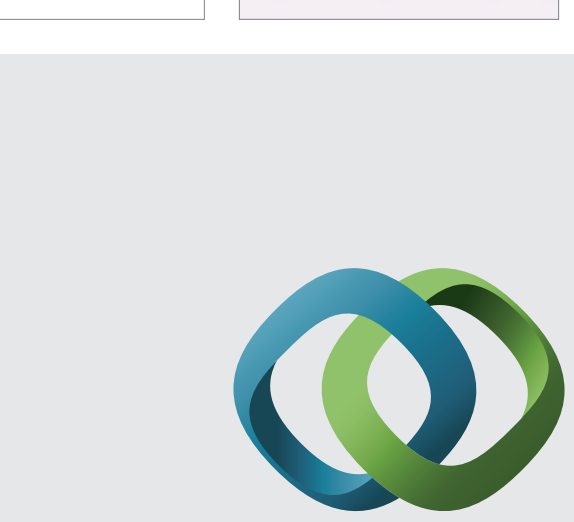

\section{Hindawi}

Submit your manuscripts at

http://www.hindawi.com
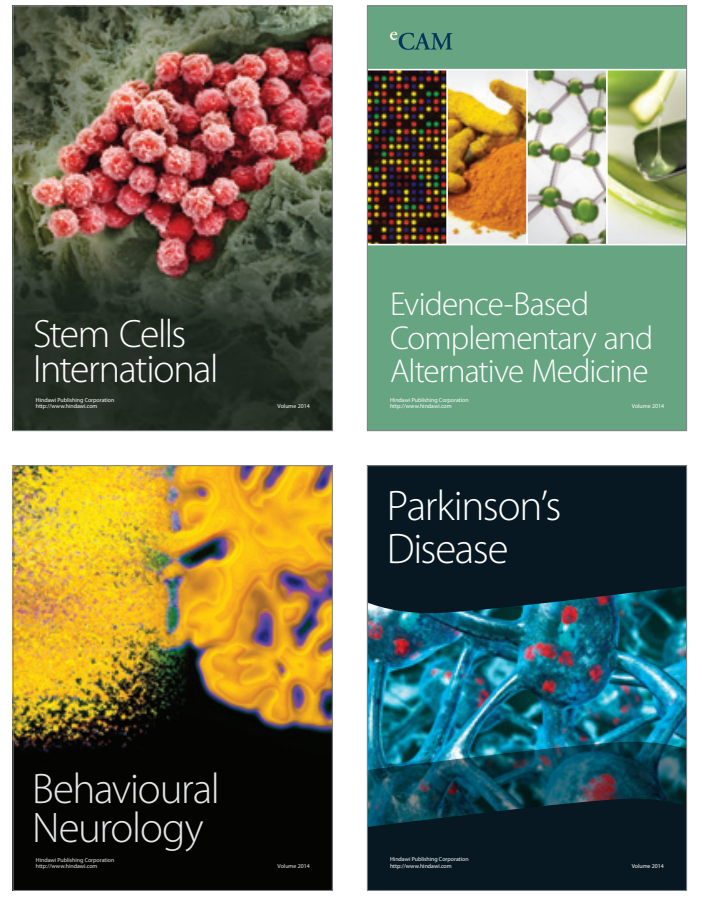
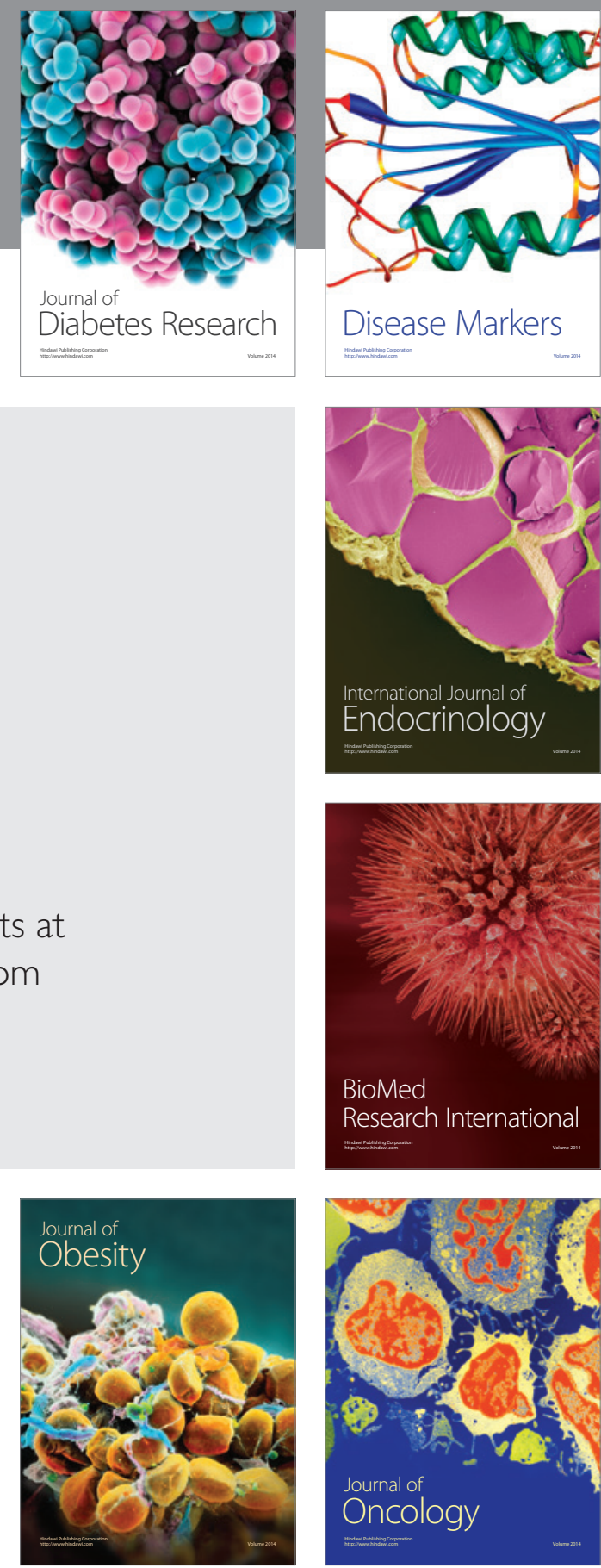

Disease Markers
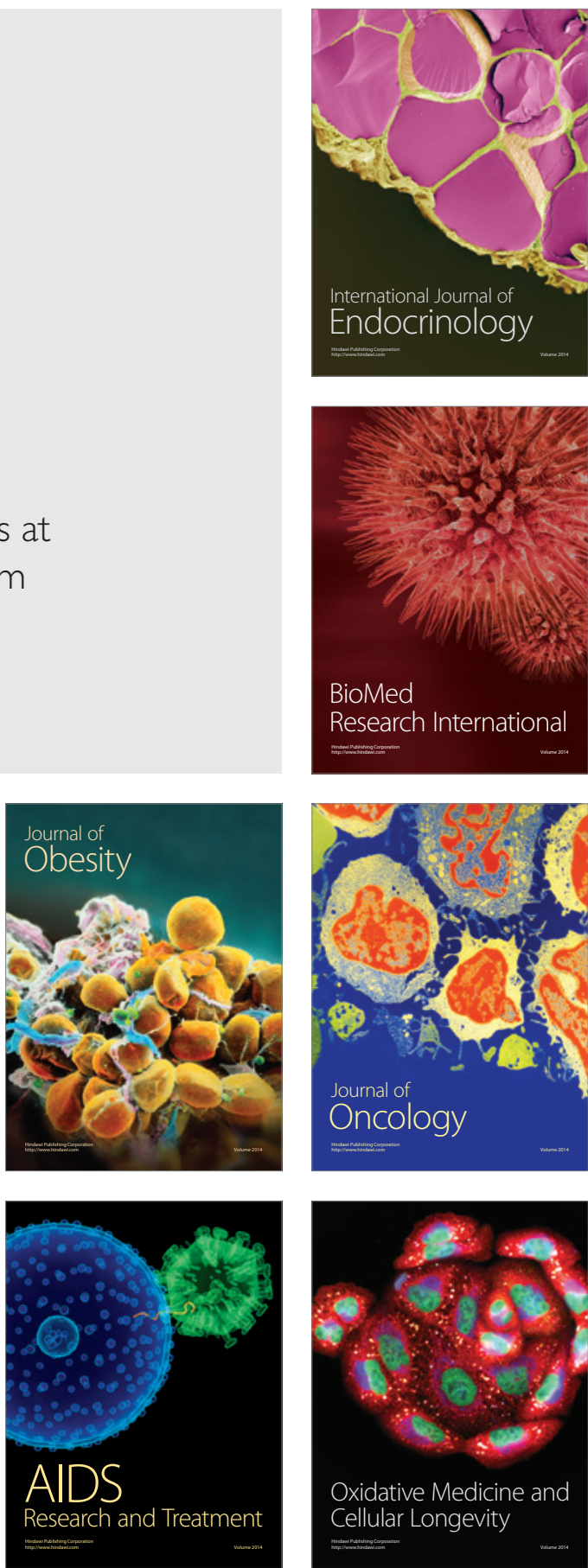